\title{
The effects of a sudden reduction in anticipated "relief"*
}

\author{
PAUL J. WOODS \\ Hollins College, Roanoke, Va. 24020
}

Rats were trained to escape from an aversive cold-water alley for five 25-trial sessions at two levels of "relief" or reinforcement magnitude. In the sixth session, the high "relief" group was shifted to low "relief" and then continued for two additional 25-trial sessions. Competing behavior was found to play an important role in preshift performance differences as well as in the immediate postshift period where a "negative contrast effect" was obtained.

A previous study dealing with the effects of shifts in reinforcement magnitude in escape conditioning reported a negative contrast effect following a sudden reduction in the amount of "relief" contingent upon a swimming-escape response (Woods, 1967). This finding was interpreted as the escape conditioning analogy to the Crespi "depression effect" commonly reported in instrumental appetitive conditioning. A corresponding sudden increase in reinforcement magnitude contingent upon the swimming-escape response, however, while leading to immediate and prolonged changes in performance, did not result in a positive contrast effect.

The present study is a further investigation of the effects of a sudden reduction in the amount of "relief" that the animal had learned to anticipate. Compared to the previous study (Woods, 1967), the present one involved greater amounts of preshift training and postshift experience, and the escape situation involved a higher level of aversive intensity.

\section{METHOD}

\section{Subjects}

Male Sprague-Dawley descendants obtained from Flow Research Animals, Inc., Dublin, Va., were used. The 32 Ss weighed approximately $150 \mathrm{~g}$ at the beginning of the study; one $S$ died during the third week.

\section{Apparatus}

The apparatus was a straight alley tank with separate goal tanks; water temperature in the alley determined the degree of aversiveness or drive stimulus intensity, and the differential between the alley and the warmer goal defined reinforcement magnitude or "relief." Temperature was automatically and precisely controlled $\left( \pm<0.1^{\circ} \mathrm{C}\right)$, and underwater photobeams, 36 in. apart and $15 \mathrm{in}$. from each end of the alley, were used to control clocks equipped with reciprocal faces, enabling the direct reading of speed scores. A more detailed description has been previously reported (Woods, 1964).

*This work was supported by Public Health Service Research Grant M-02883 from the National Institute of Mental Health. Requests for reprints should be sent to Paul J. Woods, Department of Psychology, Hollins College, Roanoke, Virginia 24020.

\begin{abstract}
Procedure
The temperature of the water in the alley was maintained at a constant $15^{\circ} \mathrm{C}$ throughout the study. This temperature is relatively high on an aversive continuum; after submerging their hands for $5 \mathrm{sec}$, human Ss describe this water temperature as cold, uncomfortable, and somewhat painful (Woods, Griffith, Page, \& Rodier, 1967). Two levels of "relief" from this aversive intensity were established by having goal tanks that were either $4^{\circ}$ or $24^{\circ} \mathrm{C}$ warmer than the alley. Ss were run in sessions of 25 trials once a week for 8 weeks. The experimental group which was shifted from high to low reinforcement conditions first escaped to the warmer goal tank; then, following the fifth trial of the sixth session, they were suddenly shifted to the goal tank that was only $4^{\circ} \mathrm{C}$ above the alley temperature. They continued escaping to this lower level of reinforcement throughout the remaining training sessions. The control group escaped with low "relief" throughout all eight sessions.

Four Es each ran four Ss in both conditions. ${ }^{1}$ On each trial, $S$ was gently lowered into the starting end of the alley tank, and when it reached the far end, it was placed in the goal tank for 20-25 sec before being returned to a detention box which was heated by a hot-air blower. $E$ recorded the total response speed from initial submersion until breaking of the final photobeam, the speed in the 36-in. midsection between the two photobeams, and noted, as well, whether this midsection of the alley had been traversed in a straight, unbroken swim or whether $S$ had made competing responses such as stopping, reversing, attempting to climb the walls, etc. These procedures, then, resulted in a general overall speed measure, a measure of swimming speed per se, and an indication of the number of noncompeting response trials. The subgroups of four Ss were run so that each $S$ had a trial before the first $S$ had the next trial, etc. Running in this manner, then, produced approximately a 4-min intertrial interval.
\end{abstract}

\section{RESULTS}

While the major concern was the shift experience, the preshift acquisition curves under the two reinforcement conditions deserve mention. These are plotted in Fig. 1 for the five preshift sessions in such a way as to allow comparison of the acquisition functions under the two levels of "relief." (The first 10 trials are shown followed by the session asymptote, and the trials are overlapped to conserve space.) The curves for the high reinforcement condition shown on the left in the figure are the relatively smooth, negatively accelerated acquisition functions that are common in many learning situations. Figure 1 shows that the "warm-up effect" gradually diminishes over weekly sessions and that a curve connecting only the first trial of each session would be a relatively smooth negatively accelerated function itself. The regularity seen in this set of functions for the high "relief" or reinforcement condition is in marked contrast to the irregularity seen in the set of functions for the low "relief" condition shown toward the right in Fig. 1. As will be documented more thoroughly below, performance under conditions of low reinforcement is not just a slower version of the same behavior that is emitted under high reinforcement. 


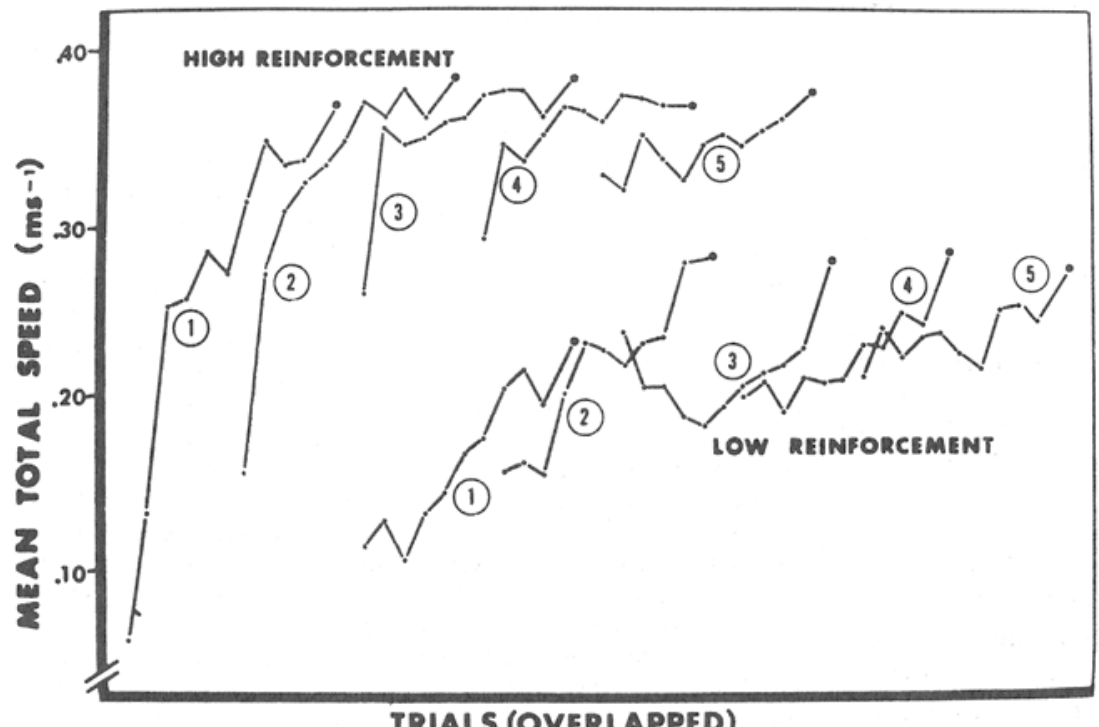

Fig. 1. Acquisition functions under the two conditions of reinforcement. (Successive weekly training sessions are shown with the first 10 trials and the session asymptote.)
Performance at different levels of reinforcement magnitude differs in other ways besides vigor.

Performance changes following the decrease in reinforcement magnitude which occurred after the fifth trial of the sixth session are shown in relation to pre- and postshift performance in Fig. 2. The asymptotes (means of final five trials) for preshift sessions are shown on the left in the figure with clear differences between the two reinforcement magnitudes. In Session 5, for example, the group escaping to high "relief" has an average total speed of $.375 \mathrm{msec}^{-1}$, which is $37 \%$ faster than the average total speed of $.273 \mathrm{msec}^{-1}$ for the groups escaping to low "relief."

As mentioned, the shift took place following the fifth trial of the sixth session; but, of course, the performance was measured on the sixth trial before the animal experienced the changed goal conditions. Hence, the difference between the sixth and seventh trial is the first indication of any reaction to the decrease in magnitude of "relief." As can be seen in Fig. 2, there is a marked and significant decrease in total response speed between these two trials from $.339 \mathrm{msec}^{-1}$ to $.278 \mathrm{msec}^{-1}$ $[t(15)=4.47, p<.001]$. This performance decrement was shown by 15 of the $16 \mathrm{Ss} .2$ From this point, there was a continual gradual decline to the ultimate low point just as had been found previously (Woods, 1967). The nonshifted control group during this period is increasing in speed, as can be seen in Fig. 2. However, the control group's final level of performance on the sixth session is comparable to what it had been during the previous four sessions. Hence, the difference between the shifted group and the control group following the reduction in "relief" (indicated by the shading in the figure) is, indeed, due to the poor performance of the shifted group, i.e., it is truly a "negative contrast effect." This difference is significant over the final 14 trials of the sixth session $[t(29)=2.33, p<.025$, one-tailed test] One week later, during the beginning of the seventh

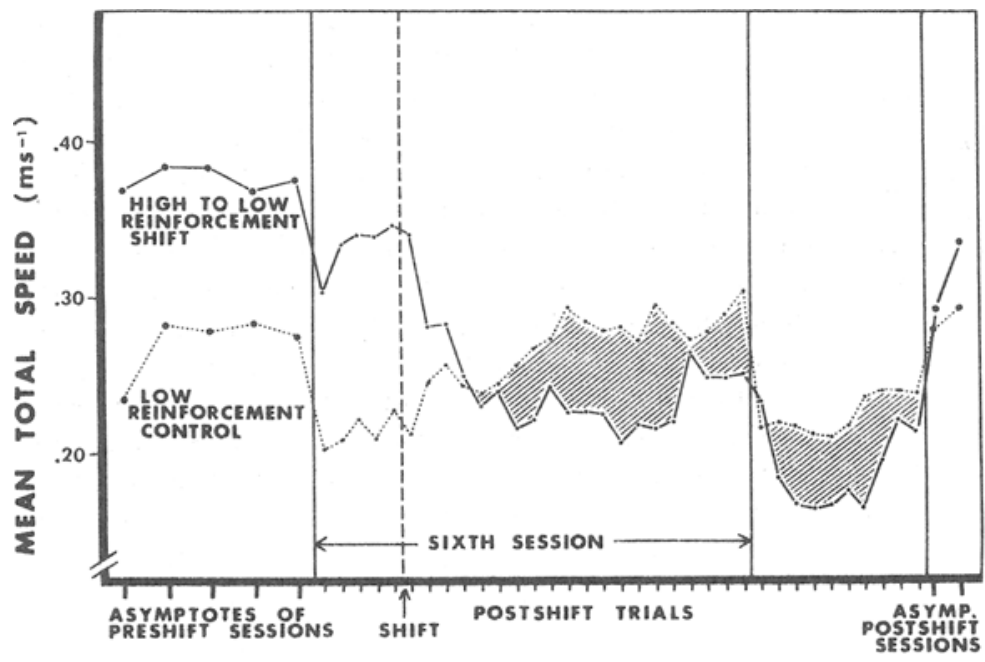

Fig. 2. Pre- and postshift performance with the "negative contrast effect" shown by the shading. 

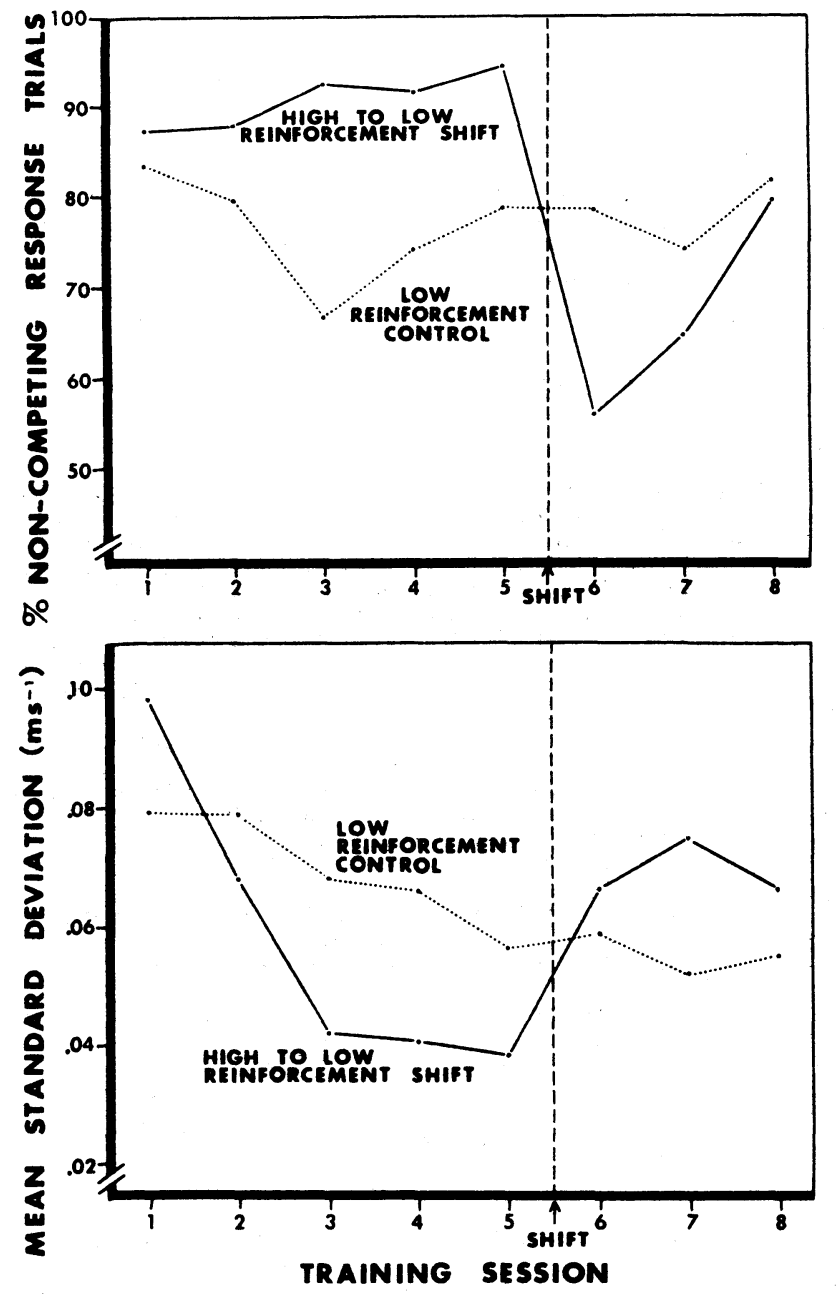

Fig. 3. Upper: Percentage of noncompeting response trials. Lower: Means of individual variability in total speed performance.

session, the shifted group was still inferior to the control group: on Trials 2-13, the former group averaged $.191 \mathrm{msec}^{-1}$ compared to $.228 \mathrm{msec}^{-1}$ for the latter group $[t(29)=1.99, p<.05$, one-tailed test $]$. By the end of the seventh session and throughout the eighth session, there were no longer any significant differences in total speed.

That the behavior emitted under different levels of "relief" was qualitatively different, as previously mentioned, can be documented further by analyzing the number of trials containing major competing responses to the required swimming escape response. As reported previously (Woods, 1967), animals escaping to high "relief" conditions are more likely to traverse the alley in a smooth, unbroken swim than are animals that are escaping to a low amount of "relief." The latter are more likely to stop, retrace, claw at the sides of the tank, etc. These differences are shown in the upper portion of Fig. 3, which plots the percentage of noncompeting response trials for the two groups over the eight sessions. First, the group escaping to high "relief" showed a significant increase in the number of noncompeting response trials over the five preshift sessions $[t(15)=2.89, p<.02]$. The low reinforcement group, on the other hand, first declined significantly from Session 1 to Session 3 [ $t(14)=3.57, \mathrm{p}<.01]$, then recovered by Session 5 to a level comparable to Session 1 and essentially stabilized from that session on. In the final preshift session, the $S s$ in the high reinforcement condition were swimming without major competing responses on an average of $94.4 \%$ of their trials as compared with $78.8 \%$ for the low reinforcement Ss $[t(29)=2.85, p<.01]$. The effect of the shift on this measure was dramatic: in the postshift trials of Session 6, the shifted group emitted major competing behaviors on an average of $46 \%$ of the trials compared to less than 6\% during Session 5. During the sixth session, the shifted group was significantly below the control group in the amount of noncompeting behavior $[t(29)=$ $2.90, \mathrm{p}<.01]$; on subsequent sessions, however, the shifted group recovered to a level comparable to that of the control group. It is these behavioral changes, then, which account for the negative contrast effect in the overall total speed measures.

The performance measure obtained over the midsection of the alley during a noncompeting response trial, i.e., when the $\mathrm{S}$ was doing nothing but swimming, is a pure measure of swimming speed itself. This measure has been previously shown to be sensitive to such variables as reinforcement magnitude and drive level, but not to within-session practice (see, for example, Woods, Davidson, \& Peters, 1964; Woods \& Feldman, 1966; Woods \& Holland, 1966; Woods \& Schutz, 1965).

In the preshift sessions, the group escaping to higher "relief" swam faster from the beginning of training. On Day 1, for example, the high "relief" group had an average swimming speed of $.401 \mathrm{msec}^{-1}$ compared to $.324 \mathrm{msec}^{-1}$ for the low "relief" group $[\mathrm{t}(30)=5.03$, $p<.001$ \}. Following the shift, there was an abrupt drop in swimming speed for all 16 shifted Ss, with the speeds of Session 6 averaging $.066 \mathrm{msec}^{-1}$ slower than the swimming speeds of Session $5[t(15)=9.83, p<.001]$. There was, however, no indication of any negative contrast effect with this measure. The shifted group was still slightly above the control group in the three postshift sessions $\left(.306 \mathrm{msec}^{-1}\right.$ vs $\left..290 \mathrm{msec}^{-1}\right)$. This result further supports the previous conclusion that competing behavior underlies the contrast effect seen in the total response speed measure.

As a final means of examining the behavioral differences obtained under the conditions of the present study, individual variability in the overall performance measure was calculated for each session. Standard deviations of the total speed scores provide some indication of the consistency with which the Ss were performing, and the mean values for the two conditions across sessions are shown in the lower portion of Fig. 3. Both groups showed a significant decline in variability 
with training throughout the five preshift sessions [ $\mathrm{t}(14)$ $=3.07, \mathrm{p}<.01$, between Sessions 1 and 5 for the control group; $\mathrm{t}(15)=8.80, \mathrm{p}<.001$, between Sessions 1 and 5 for the shifted group]. Also, the groups were significantly different from each other on all five sessions. The high "relief" group showed more variability on Session 1 [ $\mathrm{t}(30)=2.35, \mathrm{p}<.05]$, but then showed significantly less variability on each of the succeeding sessions [on Session 5 , for example, $\mathrm{t}(29)=$ $2.66, p<.02]$. On the postshift trials of Session 6, however, the shifted group showed a significant increase in variability from Session $5[t(15)=4.43, p<.001]$, and by Session 7, it was significantly more variable than the control group $[t(29)=3.19, \mathrm{p}<.01]$. This should be noted in comparison to the total speed score data for Session 7 shown in Fig. 2, where a significant negative contrast effect was still present. These data on variability in the overall speed measure serve as additional support for the interpretation made on the competing response data, and this fact is important since the total speed measures were strictly objective while the existence of competing behaviors required a judgment on the part of E.

\section{DISCUSSION}

As already mentioned, a previous study (Woods, 1967) utilized a much less aversive level from which Ss had to escape than did the present study. The alley temperature in that study was $25^{\circ} \mathrm{C}$, which human Ss rate as cool, not uncomfortable, and painless after a 5-sec exposure of the hand (Woods et al, 1967). This is to be contrasted to the present study, where a temperature was used which humans rate as cold, uncomfortable, and somewhat painful. The fact that we still obtained comparable results lends generality to the phenomenon.

But this should be evaluated with the perspective that there have been failures as well. In a series of studies in our laboratory, Yeager (1969) was unable to replicate the negative contrast effect and a shifted placebo group in a large drug study also failed to show contrast (Woods \& Steiner, 1970).

An important finding in the present study is the clear demonstration of qualitative behavioral differences in the preshift performance of the two groups which were escaping to different magnitudes of reinforcement or "relief." Ss did not merely swim faster, they actually behaved differently, and such qualitative differences must not be ignored by theoretical models.

Then, a sudden reduction in "relief" was thoroughly documented as having a disrupting effect. Increases in competing behavior and in total performance variability, as well as observations of Ss' behavior following placement in the new, colder goal tank where they struggled, squealed, jumped up the sides, and sometimes even bit $\mathbf{E}$ when removed, lead us to continue favoring what Dunham (1968) discusses as an emotional-motivational position in contrast to a perceptualmotivational position. In effect, the new low "relief" condition is frustrating to the $\mathrm{Ss}$ and it is frustrating because it fails to match the anticipated relatively high "relief" that they had previously learned to expect. Such speculation, of course, has been clearly influenced by Amsel's $(1958,1962)$ thinking related to frustrative nonreward in appetitive conditioning.

\section{REFERENCES}

Amsel, $A$. The role of frustrative nonreward in noncontinuous reward situations. Psychological Bulletin, 1958, 55, 102-119

Amsel, A. Frustrative nonreward in partial reinforcement and discrimination learning: Some recent history and a theoretical extension. Psychological Review, 1962, 69, 306-328.

Dunham, P. J. Contrasted conditions of reinforcement: A selective critique. Psychological Bulletin, 1968, 69, 295-315. Woods, P. J. Water tank apparatus for instrumental escape conditioning. Psychological Reports, 1964, 14, 167-170.

Woods, P. J. Performance changes in escape conditioning following shifts in the magnitude of reinforcement. Journal of Experimental Psychology, 1967, 75, 487-491.

woods, P. J., Davidson, E. H., \& Peters, R. J., Jr. Instrumental escape conditioning in a water tank: Effects of variations in drive stimulus intensity and reinforcement magnitude. Journal of Comparative \& Physiological Psychology, 1964, 57, 466-470.

Woods, P. J., \& Feldman, G. B. Combination of magnitude and delay of reinforcement in instrumental escape conditioning. Journal of Comparative \& Physiological Psychology, 1966, 62, 149-151.

Woods, P. J., Griffith, B. A., Page, R. P., \& Rodier, P. M. Human responses to various conditions of water temperature. Perception \& Psychophysics, 1967, 2, 157-160.

Woods, P. J., \& Holland, C. H. Instrumental escape conditioning in a water tank: Effects of constant reinforcement at different levels of drive stimulus intensity. Journal of Comparative \& Physiological Psychology, 1966, 62, 403-408.

Woods, P. J., \& Schutz, L. J. Performance in instrumental-escape conditioning following a shift in drive-stimulus intensity. Proceedings of the 73rd Annual Convention of the American Proceedings of the 73rd Annual Conven
Psychological Association, 1965, 23, 24.

Woods, P. J., \& Steiner, S. S. Reinforcement reduction in escape conditioning: The effects of chlorpromazine and methamphetamine. Paper presented at the meeting of the Eastern Psychological Association, Atlantic City, April 1970.

Yeager, D. L. Instrumental escape conditioning in a water alley: The effects of a high-low shift in reinforcement magnitude. Unpublished MA thesis, Hollins College, 1970.

\section{NOTES}

1. The author wishes to thank Terry J. Crawford, Katherine French, Janie B. Humphreys, and F. Catherine McCaslin for their help in collecting and analyzing these data.

2. It is interesting to note that the one $S$ who did not show a decrement on the first postshift trial was, in fact, the fastest responder in the entire group. His average total speed for the fifth session, for example, was $.505 \mathrm{msec}^{-1}$ compared to an average of $.354 \mathrm{msec}^{-1}$ for the remaining $15 \mathrm{Ss}$. He did decline ty the second postshift trial, however, and his subsequent performance fell off markedly.

(Received for publication August 11, 1972.) 